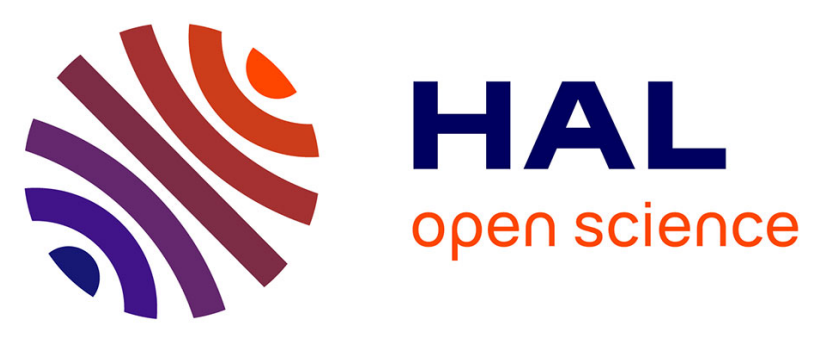

\title{
Gammarus pulex (Crustacea: Amphipoda) avoids increasing water temperature and intraspecific competition through vertical migration into the hyporheic zone: a mesocosm experiment
}

Ross Vander Vorste, Florian Mermillod-Blondin, Frédéric Hervant, R. Mons, T. Datry

\section{To cite this version:}

Ross Vander Vorste, Florian Mermillod-Blondin, Frédéric Hervant, R. Mons, T. Datry. Gammarus pulex (Crustacea: Amphipoda) avoids increasing water temperature and intraspecific competition through vertical migration into the hyporheic zone: a mesocosm experiment. Aquatic Sciences Research Across Boundaries, 2017, 79 (1), pp.45-55. 10.1007/s00027-016-0478-z . hal-01493842

\section{HAL Id: hal-01493842 \\ https://hal-sde.archives-ouvertes.fr/hal-01493842}

Submitted on 16 May 2020

HAL is a multi-disciplinary open access archive for the deposit and dissemination of scientific research documents, whether they are published or not. The documents may come from teaching and research institutions in France or abroad, or from public or private research centers.
L'archive ouverte pluridisciplinaire HAL, est destinée au dépôt et à la diffusion de documents scientifiques de niveau recherche, publiés ou non, émanant des établissements d'enseignement et de recherche français ou étrangers, des laboratoires publics ou privés. 


\author{
1 Gammarus pulex (Crustacea: Amphipoda) avoids increasing water temperature and intraspecific \\ 2 competition through vertical migration into the hyporheic zone: a mesocosm experiment.

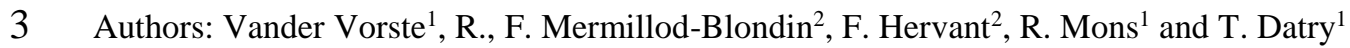 \\ 4 Affiliations: \\ $5 \quad{ }^{1}$ IRSTEA, UR MALY, 5 rue de la Doua, CS70077, F-69626 Villeurbanne, France \\ 6 2LEHNA, UMR CNRS 5023, Ecologie des Hydrosystèmes Naturels et Anthropisés, Université de Lyon, \\ 7 Université Lyon 1, 6 rue Raphael Dubois, 69622 Villeurbanne, France \\ 8 \\ 9 Corresponding author:
}

R. Vander Vorste, IRSTEA, UR MALY, Centre de Lyon-Villeurbanne, 5 Rue de la Doua CS70077 69626

Villeurbanne Cedex, France. Tel (33) 4.72.20.10.87 Fax (33) 4.78.47.78.75, ross.vander-vorste@ irstea.fr

\section{Abstract:}

The saturated sediments below and adjacent to the riverbed (i.e., hyporheic zone) can be a refuge for biota during disturbances, such as drying. Prior to drying, organisms are constrained by abiotic and biotic factors (e.g., water temperature, competition) and may respond through vertical migration into the hyporheic zone. However, it remains unclear when these factors become harsh enough to trigger this response. Furthermore, potential consequences of using the hyporheic zone, which is often food-limited, on the survival, ecosystem function and physiology of organisms are unknown. Using 36 mesocosms, the hypotheses that i) Gammarus pulex migrates into the hyporheic zone to avoid increasing surface water temperature and intraspecific competition and ii) migration would have negative consequences on the survival, leaf mass consumption and energy stores of organisms were tested. Three levels of temperature $\left(15,20,25^{\circ} \mathrm{C}\right)$ and species density (low, medium, high) were manipulated in a factorial design over 15 days. Increased temperature to $25^{\circ} \mathrm{C}$ and a 3 -fold increase in density both caused G. pulex to migrate into the hyporheic zone, but the interaction of these factors was not synergistic. Importantly, the survival, leaf consumption and glycogen content were reduced in high temperature and density treatments, indicating tradeoffs between tolerating harsh surface conditions and limitations in the hyporheic zone. Identifying that the hyporheic zone is used by invertebrates to avoid high water temperature and 
intraspecific competition is a key finding considering the global-scale increases in temperature and flow intermittence, yet its capacity to provide refuge is likely temporally limited.

Key words:

stream drying, refuge, resistance, resilience, avoidance behavior, invertebrates

\section{Introduction}

32 The saturated interstitial areas beneath the riverbed and into the adjacent banks (i.e., hyporheic zone; White, 33 1993) have long been recognized for their potential to serve as a refuge for biota during disturbances (i.e., 34 hyporheic refuge hypothesis; Palmer et al. 1992, Dole-Olivier et al. 1997, Stubbington 2012). They may also be 35 a major source of colonization promoting the resilience of invertebrates (i.e., capacity to recover, Stanley 1994) 36 following disturbances, such as flooding and drying (e.g., Holomuzki and Biggs 2007, Kawanishi et al. 2013, 37 Vander Vorste et al. 2015 in review). Despite substantial empirical evidence showing that the physical characteristics of the hyporheic zone (e.g., \% fine sediment, hydraulic conductivity, vertical hydraulic gradient) alter its potential to serve as a refuge (e.g., Navel et al. 2010, Descloux et al. 2013, Mathers et al. 2014), the abiotic or biotic factors invertebrates respond to through vertical migration into the hyporheic zone remain speculative (Stubbington 2012). Among these factors, water temperature and biotic interactions are thought to be two of the most influential in triggering a behavioral response for stream invertebrates to enter the hyporheic zone (James et al. 2008, Wood et al. 2010, Stubbington et al. 2011).

Understanding the effects of increasing water temperature on the vertical migration of invertebrates into the hyporheic zone is critical in a context of global warming and water scarcity (Postel 2000, Datry et al. 2014, Jaeger et al. 2014). In many rivers, the increase in water temperature observed over the past 100 years ranges between 0.009-0.077 ${ }^{\circ} \mathrm{C} \mathrm{y}^{-1}$ (Kaushal et al. 2010) and higher maximum temperatures (e.g., Mantua et al. 2010) are exceeding the physiological tolerance of aquatic organisms (Mouthon and Daufresne 2006, Wenger et al. 2011, Stewart et al. 2013a). For example, a $1.5^{\circ} \mathrm{C}$ increase in mean temperature combined with historically high summer temperatures $\left(29.5^{\circ} \mathrm{C}\right.$ max. $)$ caused dramatic and long-lasting $(>1 \mathrm{yr})$ declines in mollusk richness and diversity in the Saône River, France (Mouthon and Daufresne 2006). Moreover, increasing water scarcity issues and subsequent low flow, flow cessation and drying events in river systems (Postel 2000, Datry et al. 2014, Jaeger et al. 2014) exacerbate the general trend in water temperature increase. For example, during the initial 4 contraction phase of drying streams, water temperature can reach above $25^{\circ} \mathrm{C}$ (e.g., Boulton 1989, Ludlam and 
Magoulick 2010). Insect larvae (e.g., Ephemeroptera, Plecoptera, Trichoptera), and crustaceans (e.g., Amphipoda, Isopoda) experience drastic increases in mortality between $21-25^{\circ} \mathrm{C}$ (Stewart et al. 2013a, Foucreau et al. 2014). To avoid thermal stress, invertebrates can migrate into the hyporheic zone, which is often several degrees cooler and remains buffered from highly variable surface temperatures (Constantz and Thomas 1997, Evans and Petts 1997). However, it is unknown at what temperatures invertebrates vertically migrate into the hyporheic zone, limiting our capacity to understand and predict the effects of global change on river community resilience. As climate change and water abstraction will continue to challenge river communities, quantifying the potential of the hyporheic zone to act as a refuge will be a key step towards predicting future responses of aquatic invertebrates (Keppel et al. 2015).

In addition to increased water temperature, vertical migration may occur when levels of biotic interactions increase, resulting notably from the contraction of aquatic habitat occurring during low flow, flow cessation and river drying (e.g., Power et al. 1985, Ludlam and Magoulick 2010). In particular, intraspecific competition for space and food can increase greatly following flow cessation (Lake 2003), as invertebrate densities reach up to 35000 individuals (ind.) $\mathrm{m}^{-2}$ (e.g., Acuña et al. 2005). High density of Chironomus riparius (Diptera) resulted in up to $75 \%$ mortality of early instars, delayed development and increased migration to avoid competition (Silver et al. 2000). The hyporheic zone may provide refuge from intraspecific competition occurring on the surface (James et al. 2008, Stubbington et al. 2011); particularly because invertebrate densities in the hyporheic zone are comparatively lower (Datry 2012, Capderrey et al. 2013). Furthermore, biotic interactions may increase (e.g., Scherr et al. 2010), decrease (e.g., Jiang and Morin 2004), or remain unaffected (e.g., Wooster et al. 2011) at high water temperatures, subsequently affecting vertical migration of surfacedwelling invertebrates into the hyporheic zone. Yet the constant interplay between water temperature and intraspecific competition in the natural environment render their effects difficult to disentangle using field surveys (Heino et al. 2015). Experimental approaches (e.g., mesocosms) can advance our understanding of the responses of invertebrates to multiple abiotic and biotic factors (Stewart et al. 2013b), and have been crucial to understanding vertical distribution of invertebrates at surface water and hyporheic zone interface (e.g., Nogaro et al. 2009, Navel et al. 2010, Vadher et al. 2015).

Despite the potential for invertebrates to seek refuge in the hyporheic zone to avoid the harmful effects of water temperature and/or biotic interactions occurring on the surface, their survival, ecosystem function and physiology may be jeopardized because food resources are often limited or of poor quality (Hervant et al. 1997, Burrell and Ledger 2003, Danger et al. 2012). For example, the surface invertebrate, Gammarus fossarum, 
85

1

subjected to starvation showed immediate hyperactivity and experienced mortality after 20 days (Hervant et al.

86 1997). Unless invertebrates can return to the surface to consume leaf litter (e.g., Elliott 2005, Navel et al. 2010), the decomposition of leaf litter on the surface will be considerably reduced when surface detritivores enter the hyporheic zone. Moreover, at the physiological level, invertebrate triglycerides and glycogen contents, two major energy stores involved in reproductive physiology and defense against environmental stress, may be considerably reduced within 1-2 weeks of the absence of food (Hervant et al. 1999). Therefore, use of a foodlimited environment (the hyporheic zone) by invertebrates to avoid high temperatures and biotic interactions on the surface represents a tradeoff that may undermine the capacity of the hyporheic zone to provide refuge during disturbances.

In this study, we measured the effect of temperature and intraspecific competition on the vertical migration of the common stream shredding detritivore, Gammarus pulex (Crustacea: Amphipoda) into the hyporheic zone. We hypothesized that the hyporheic zone would be used as a refuge by this species to avoid high water temperature and intraspecific competition. We also hypothesized that migration into hyporheic zone would have negative effects on the survival, leaf consumption and energy stores of organisms. Based on these hypotheses, we predicted that: i) a higher proportion of organisms would migrate into the hyporheic zone as water temperature and species density increased, and ii) that the survival, leaf mass consumption rate and energy stores would decrease at the highest temperature and species densities. We also examined the potential interaction effect (synergistic, antagonistic, additive) of water temperature and intraspecific competition on the vertical migration of G. pulex into the hyporheic zone.

\section{Methods}

Study organism and collection site

Gammarus pulex is a widespread and common surface-dwelling shredder that is important in leaf litter degradation across European streams (MacNeil et al. 1997, Dangles and Malmqvist 2004, Piscart et al. 2011). All individuals were collected from a small stream near Dijon, France $\left(47^{\circ} 24^{\prime} 13^{\prime \prime} \mathrm{N}, 04^{\circ} 52^{\prime} 57^{\prime \prime} \mathrm{E}\right)$, where species identity was previously confirmed through DNA analysis (Foucreau et al. 2013). During collection, sieves between $2.5-5.0 \mathrm{~mm}$ were used to select similar-sized individuals. Individuals were returned to a temperaturecontrolled $\left(15 \pm 2^{\circ} \mathrm{C}\right)$ room and allowed to acclimatize to laboratory temperature, water quality and food source for a 14-day period (Navel et al. 2010) before the start of the experiment. Water temperature was kept constant $\left(15 \pm 2^{\circ} \mathrm{C}\right)$ using a thermostatic water pump (TECO, Ravena, Italy) and oxygen concentrations were maintained 
114 near saturation with oxygen bubblers. During this time, individuals were fed alder leaves (Alnus glutinosa)

collected in the autumn at a nearby river bank, air-dried and stored at room temperature.

\section{Mesocosm description}

Mesocosms $(\mathrm{n}=36)$ were constructed from opaque PVC tubing $(70 \mathrm{~cm}$ length $\times 25 \mathrm{~cm}$ diameter, $2 \mathrm{~mm}$ thickness) with a PVC end cap, forming a vertical column (Fig. 1). To enumerate the individuals that migrated into the hyporheic zone, mesocosms were constructed in two parts, a 30-cm surface zone and a 40-cm hyporheic zone. These parts were joined during the experiment using PVC flanges ( $25 \mathrm{~cm}$ diameter) and allowed quick separation at the end of the experiment. Mesocosms were filled to a height of $50 \mathrm{~cm}$ with gravel substrate $(10-14$ mm) extracted from the Rhône River, France, leaving $10 \mathrm{~cm}$ of substrate in the surface zone (Fig. 1).

Dechlorinated tap water was continuously pumped from a 1000-L tank into the bottom of the mesocosms using two 24-channel peristaltic pumps at a rate of $1.25 \mathrm{~L} \mathrm{~h}^{-1}$, creating a slightly positive vertical hydraulic gradient (i.e., upwelling movement of water) and constituting a complete renewal of mesocosm water volume in $24 \mathrm{~h}$ (Fig. 1). Water drained through a hole $(2 \mathrm{~cm}$ diameter), screened $(0.5 \mathrm{~cm}$ mesh) to prevent invertebrates from escaping, located $5 \mathrm{~cm}$ below the top of each column. Surface water was aerated using an oxygen bubbler to keep dissolved oxygen $\left(\mathrm{O}_{2}\right)$ concentrations between $8.5-9.5 \mathrm{mg} \mathrm{L}^{-1}$. A 12:12-h light:dark cycle was applied to the surface water zone using Grolux ( 35 W, 8500 K, Sylvania Inc., Noida, India) aquarium lights above mesocosms (Fig. 1).

\section{Experimental design}

Surface water temperature and species density were manipulated at 3 levels each in a factorial design over a 15day period. Three treatments of temperature $\left(15,20\right.$ and $\left.25^{\circ} \mathrm{C}\right)$ were tested $(\mathrm{n}=12$ mesocosms per temperature). To heat the surface water, a 10-m long heated cable $(0.5 \mathrm{~cm}$ diameter) (Hydrokable, Hydor Inc. Sacramento, CA USA) was buried into the surface substrate and coiled around the inner wall of the mesocosms to the top of the surface zone. Surface water temperature was controlled using an electronic thermostat $\left( \pm 0.1^{\circ} \mathrm{C}\right)$ (Hobby, Dohse Aquaristik GmbH \& Co., Grafschaft, Germany). Surface and hyporheic water temperature was recorded hourly using iButton loggers (Maxim Integrated, San Jose, CA USA). For the unheated temperature treatment $\left(15^{\circ} \mathrm{C}\right)$ (see below), an equally sized cable was similarly installed to account for the possible effect cables might have on vertical migration. Water temperature in the hyporheic zone was kept at $15.5 \pm 0.5^{\circ} \mathrm{C}$ (mean $\pm \mathrm{SD}$ ) throughout the experiment, representing an approximate mean temperature reported from several rivers and providing a thermal refuge for organisms (Constantz and Thomas 1997, Evans and Petts 1997, Stubbington et al. 2011). For 
143 the first 24 hours of the experiment, water temperature was kept constant $\left(15.2 \pm 0.3^{\circ} \mathrm{C}\right)$ across all treatments.

After this acclimatization period, temperatures were increased to the treatment level at a rate of $0.2^{\circ} \mathrm{Ch}^{-1}$ for $20^{\circ} \mathrm{C}$ and $0.4^{\circ} \mathrm{C} \mathrm{h}^{-1}$ for $25^{\circ} \mathrm{C}$ treatments over a 24-h period to avoid thermal shock of the organisms (Stewart et al. 2013a). Surface water temperature was then kept constant until the end of the experiment.

Three species density treatments, based on previous field surveys reporting G. pulex densities (Welton 1979, Elliott 2005), were tested ( $\mathrm{n}=12$ mesocosms per density). A low density treatment of 40 ind. mesocosm ${ }^{-1}$, corresponding to 815 ind. $\mathrm{m}^{-2}$, was used to represent density treatments having little or no intraspecific competition. Density was increased 3-fold to 120 ind. mesocosm ${ }^{-1}\left(2444\right.$ ind. $\left.\mathrm{m}^{-2}\right)$ to induce moderate levels of intraspecific competition (i.e., medium density). A high density treatment of 500 ind. mesocosm ${ }^{-1}$ (10 183 ind. $\mathrm{m}^{-2}$ ) was used to induce high levels of intraspecific competition. For each treatment, individuals were counted by hand before being transferred into mesocosms using a small-hand net at the start of the experiment.

\section{Proportion of individuals migrated into the hyporheic zone}

The proportion of individuals that migrated into the hyporheic zone was quantified after 15 days by separating 156 the surface and hyporheic zones of the mesocosms. For this, mesocosms were placed into a $60 \times 80 \times 40 \mathrm{~cm}$

Survival of organisms

165 Upon collection, all individuals were placed in white sorting trays and visually inspected for any movement.

plastic wash basin, with care taken to avoid agitation of the surface water that may cause organisms to redistribute vertically. The hyporheic zone was isolated from the surface zone by removing the stainless steel bolts that attached the two parts of the mesocosm and rapidly sliding the surface zone into the large basin, leaving the hyporheic zone of the mesocosm undisturbed. During this process, the water level in the columns was maintained until the moment of separation to avoid incidental migration of organisms into hyporheic zone. Substrate from each section was then sieved $(500 \mu \mathrm{m})$ separately to recover all individuals from their respective zone.

\section{Individuals that did not survive the experiment were counted and separated from living individuals so they were} not used for assays of triglycerides and glycogen (see below). Because G. pulex is known to feed on its dead conspecies (MacNeil et al. 1997), individuals not found at the end of the experiment were presumed to be dead and consumed. Few individuals $(<1 \%)$ appeared to be killed during the sampling effort (i.e. sieving); however, 
170

1

these individuals could not be reliably separated from individuals that did not survive the experimental treatments.

\section{Measuring leaf consumption rate}

In each mesocosm, $220 \pm 10 \mathrm{mg}$ of alder leaves with primary veins removed, dried at $60^{\circ} \mathrm{C}$ for 24 hours, were enclosed in $15 \times 6$-cm plastic mesh $(10 \mathrm{~mm}$ diameter) bags. This mesh size allowed $G$. pulex to enter the bags freely and consume leaf litter. Leaf litter was pre-conditioned by immersing in river water for 10 days to allow for microbial colonization (mainly aquatic hyphomycetes) and improve leaf palatability (Navel et al. 2010). After conditioning, one leaf litter bag was placed on the substrate surface of each mesocosm before the start of the experiment. Following the experiment, leaves were collected, dried at $60^{\circ} \mathrm{C}$ for $24 \mathrm{~h}$ and re-weighed. Leaf consumption rates (mg. ind..$^{-1}$ day $\left.^{-1}\right)$ were calculated as ((initial dry leaf mass)-(final dry leaf mass))/((\# of individuals)*15 days). To correct final leaf mass consumption for leaching and microbial consumption not attributable to G. pulex, a temperature-specific correction factor was calculated based on the leaf mass loss in bags $(\mathrm{n}=9)$ immersed in additional columns void of $G$. pulex for 15 days at each temperature level (Navel et al. 2010). Consumption rates were calculated based on the initial number and also the final number of individuals per mesocosm to account for survivorship and ensure that analyses of water temperature and species density effects on consumption rate were not biased by the method of calculating consumption rate.

\section{Measuring triglycerides and glycogen contents}

87 For triglycerides and glycogen assays, individuals collected at the end of the experiment were dried using an 188 absorbent cloth, freeze-dried and weighed in groups of 3-4 individuals. Three replicate groups from each 189 mesocosm were collected to establish mean triglycerides and glycogen contents. Groups were weighed $( \pm 0.1$ $\mathrm{mg}$ ) and then ground into powder with a small mortar in pre-weighed glass tubes. Triglycerides and glycogen ( $\mu$ mol.g $\mathrm{g}^{-1}$ dry mass) were extracted using standard enzymatic methods with prepared solutions (Sigma-Aldrich, Saint-Quentin Fallavier, France) described in further detail in Hervant et al. (1995) and Salin et al. (2010). Assays were made using an Aquamate spectrophotometer (Thermo Scientific Inc., Waltham, MA, USA) at $25^{\circ} \mathrm{C}$.

\section{Data analysis}

Differences in the mean proportion of G. pulex that migrated into the hyporheic zone, percent survivorship, leaf mass consumption rate and triglycerides and glycogen contents between treatments were tested using a twofactor (two-way) analysis of variance (ANOVA). The design was a 3 (temperature levels: $\left.15,20,25^{\circ} \mathrm{C}\right) \times 3$ 
198 (species density levels: low, medium, high) factorial design with interactions. Post hoc Tukey HSD multiple

comparisons were used to compare mean levels within temperature and density treatment factors. Plotted residual variances and Levene's test were used to check for homogeneity of variance and normality and subsequently all percentages were $\operatorname{arc}(\sqrt{ }-\mathrm{x})$-transformed and leaf mass consumption rates and triglycerides and glycogen content values were $\log _{10}(\mathrm{x})$-transformed to meet these assumptions. ANOVA and post hoc comparisons were made using $R$ (version 3.1.1; R Project for Statistical Computing, Vienna, Austria).

\section{Results}

Effect of water temperature and species density on G. pulex migration into the hyporheic zone.

The proportion of individuals that migrated into the hyporheic zone tended to increase as water temperature and species density increased (ANOVA, temperature effect: $F_{2,27}=4.28, P=0.024$, density effect: $F_{2,27}=11.354, \mathrm{P}$ $<0.001$; Table 1, Fig. 2). The proportion of organisms that migrated was higher in the $25^{\circ} \mathrm{C}$ treatments than at $15^{\circ} \mathrm{C}$ (Tukey HSD, $P=0.030$; Fig. 2), but not different than the proportion measured in the $20^{\circ} \mathrm{C}$ treatments. At 210 high species density, the proportion of organisms that migrated was greater than in medium density (Tukey 211 HSD, $P=0.003$ ) and low density treatments (Tukey HSD, $P<0.001$; Fig. 2). The effect of water temperature on

Effect of water temperature and species density on the leaf mass consumption rate of G. pulex.

Leaf consumption rate of $G$. pulex based on the initial density was affected by water temperature, species density and their interaction (ANOVA, temperature $\times$ density effect: $F_{2,26}=15.93, P<0.001$, Table 1, Fig. 3).

224 Consumption rate in the $20^{\circ} \mathrm{C}$ and $25^{\circ} \mathrm{C}$ treatments was lowest at medium and high species densities compared effect: $F_{4,27}=1.65, P=0.191$; Table 1, Fig. 2 ).

Effect of water temperature and species density on survival of G. pulex

The proportion of organisms that survived the experiment decreased as water temperature increased and there was an interaction effect of water temperature and species density (ANOVA, temperature $\times$ density effect: $F_{2,27}$ $=5.64, \mathrm{P}=0.002$; Table 1 , Table 2). The proportion of survival across low and medium densities was lowest at $25^{\circ} \mathrm{C}$ compared to survival measured at 15 and $20^{\circ} \mathrm{C}$ (Tukey HSD, $\mathrm{P}<0.001$ for all), whereas survival in the high density treatment at $25^{\circ} \mathrm{C}$ differed from survival in the high density treatment at $15^{\circ} \mathrm{C}$ (Tukey HSD, $\mathrm{P}=$ 0.02; Table 2) but not the high density treatment at $20^{\circ} \mathrm{C}$. 
to low density (Tukey HSD, $\mathrm{P}<0.001$ for all) but at $15^{\circ} \mathrm{C}$, different consumption rates were only detected between low and high density treatments (Tukey HSD, P $<0.001$, Fig. 3). Similarly, consumption rate based on the final density was also affected by the interaction of water temperature and species density (results shown in Appendix SI).

Triglycerides and glycogen contents of organisms using the hyporheic zone

Mean triglycerides content did not differ among the levels of water temperature, species density nor by the interaction of these factors (Table 1). For mean glycogen content, the effect of water temperature was not consistent across different levels of species density (ANOVA, temperature $\times$ density effect: $F_{4,26}=4.013, P=$ 0.012; Table 1; Fig. 4). Glycogen content at high and medium densities was lower than glycogen content at low density in the $20^{\circ} \mathrm{C}$ treatment (Tukey HSD, $P=0.004$ for both), whereas there was no difference in glycogen content among low, medium and high densities at $15^{\circ} \mathrm{C}$.

\section{Discussion}

Influence of water temperature and species density on vertical migration into the hyporheic zone

In agreement with our first prediction, both increasing water temperature and intraspecific competition led to the migration of G. pulex into the hyporheic zone. These findings imply hyporheic refuge use is an active process in which invertebrates use abiotic and biotic cues to avoid the harsh surface conditions that coincide with low flow, flow cessation and drying events. Water temperature above $20^{\circ} \mathrm{C}$ caused a higher proportion of individuals to use the hyporheic zone. This threshold closely matches the temperature $\left(24^{\circ} \mathrm{C}\right)$ when G. pulex survival becomes drastically reduced in short-term (10 days) enclosed exposures (Foucreau et al. 2014). For intraspecific competition, a 3 -fold increase in species density $\left(2400\right.$ ind. $\left.\mathrm{m}^{-2}\right)$ led to a higher proportion of individuals using the hyporheic zone. In previous behavior experiments with G. pseudolimnaeus, Williams and Moore (1985) found a 3.5-fold increase in species density increased the number of individuals entering the substrate. Our results mirror those from two previous studies investigating hyporheic refuge use by invertebrates (Wood et al. 2010, Stubbington et al. 2011). Wood et al. (2010) reported peak invertebrate densities in the hyporheic zone when surface water temperature around $20^{\circ} \mathrm{C}$ was reached in the Little Stour River, UK; whereas Stubbington et al. (2011) found the highest proportion of G. pulex in the hyporheic zone, relative to the surface, during a lowflow period in the River Lathkill, UK, when the highest density (2449 ind. $\mathrm{m}^{-2}$ ) occurred. Our mesocosm approach complemented these field surveys by disentangling the individual and combined effects of water 
253

1

temperature and intraspecific competition and identifying thresholds that will help predict the responses of invertebrates to low flow, flow cessation and river drying.

Biotic interactions (e.g., competition, predator-prey relationships) can intensify with increasing water temperature (Burnside et al. 2014), leading to unexpected responses of species in aquatic systems (Ormerod et al. 2010). However, in this study, the effect intraspecific competition of G. pulex on the proportion of individuals that migrated into the hyporheic zone did not appear to increase when temperatures were increased up to $25^{\circ} \mathrm{C}$ (i.e., additive response). The absence of a synergistic response may be attributed to the behavior of G. pulex at temperatures above its thermal tolerance. At temperatures above its thermal tolerance, activity rates and metabolism can decrease sharply (e.g., Foucreau et al. 2014), which may have led to a decrease in conspecific encounters, hence, reducing competition (Wooster et al. 2011). Therefore, biotic interactions may increase with water temperature until the point when thermal tolerance is exceeded, which is between $21-25^{\circ} \mathrm{C}$ for most aquatic invertebrates (Stewart et al. 2013a, Foucreau et al. 2014), and individuals reduce their activity in a final attempt to conserve energy and avoid death.

Our results, along with those from previous field studies (e.g., Wood et al. 2010, Stubbington et al. 2011), bolster evidence that the hyporheic zone is an important refuge for riverine invertebrates avoiding increased water temperatures and biotic interactions. These results have important implications considering the projected global-scale increases in water temperatures and flow intermittence (Postel 2000, van Vliet et al. 2013, Datry et al. 2014). In particular, water stressed regions, such as the American Southwest, may see a $27 \%$ increase in the median number of days of flow cessation and a 15-day increase drying event duration by mid-century, respectively (Jaeger et al. 2014). Changes in flow regime will be coupled with average increases in global mean and maximum river water temperatures up to $1.6^{\circ} \mathrm{C}$ which will, in turn, increase evaporation and drying rates (van Vliet et al. 2013). If organisms can survive temporarily in the hyporheic zone and return to the surface when conditions become favorable, it is likely that, in at least some systems (e.g., alluvial rivers), the hyporheic zone can be the primary source of resilience for invertebrate communities (Vander Vorste et al. in review).

Future experiments may aim to test the effects of different abiotic and biotic factors that could also influence invertebrate use of the hyporheic zone. For example, dissolved oxygen saturation in receding river pools can be as low as $6 \%$ (e.g., Boulton 1989) and when coupled with high water temperatures will likely increase the negative effects on invertebrates and consequently, migration of invertebrates into the hyporheic zone would be strongly increased. Depth of the water table below the riverbed may also be an important factor limiting the colonization and return to surface for invertebrates (Vander Vorste et al. in review). Furthermore, 
interspecific competition and predation often increase simultaneously in drying rivers (Lake 2003) and may trigger migration of invertebrates into the hyporheic zone (Stubbington 2012). Invertebrate migration into hyporheic zone may decrease predation risk from fish and large invertebrates (e.g., Fairchild and Holomuzki 2005), and reduce top-down effects in river pools (Boersma et al. 2014). Finally, the direction of vertical hydraulic gradient (i.e., upwelling, downwelling) is likely an overriding physical force controlling vertical migration of invertebrates (Olsen and Townsend 2003, Capderrey et al. 2013, Mathers et al. 2014). In this study, the fact that mesocosms had slightly upwelling water strengthens evidence that G. pulex actively sought refuge in the hyporheic zone, rather than passively following the direction of water movement. In general, higher abundances of surface invertebrate are found in downwelling reaches (e.g., Dole-Olivier et al. 1997, Olsen and Townsend 2003, Capderrey et al. 2013), presumably aided by the downward movement of water. Therefore, it is expected that $G$. pulex would show a greater response to enter the hyporheic zone in downwelling river reaches. Although, vertical migration may have been related to the rheophilic nature of G. pulex or its ability to detect cooler temperatures in the upwelling water. Future mesocosm experiments can facilitate exploration into how these various factors will influence hyporheic zone use by invertebrates in drying rivers.

\section{Decreased survival, leaf litter consumption and energy stores}

In agreement with our second prediction, use of the hyporheic zone as a refuge had negative effects on survival, leaf litter consumption and energy stores of G. pulex. In this study, the hyporheic zone in mesocosms mimicked conditions in the natural streams, where the availability of food resources are generally limited and/or of poor quality (Burrell and Ledger 2003, Danger et al. 2012). Consequently, the low rates of survivorship (39 $\pm 7 \%$; mean $\pm \mathrm{SD}$ ) and decreased glycogen content of G. pulex in high temperature treatments suggested that starvation could have become a factor during this 15-day experiment. Previous studies have shown surface invertebrates appear highly susceptible to mortality during periods of starvation (Hervant et al. 1997, 1999), especially compared to hypogean taxa. Therefore, food resources may be an important limiting factor that influences invertebrate survival in the hyporheic zone.

As a consequence of migration into the hyporheic zone, the processing of leaf litter by invertebrates on the riverbed may be substantially reduced during periods of low flow, flow cessation, and stream drying (Corti et al. 2011, Datry et al. 2011, Dehedin et al. 2013). In this study, a $63 \pm 7 \%$ reduction in leaf litter consumption per individual between 20 and $25^{\circ} \mathrm{C}$ suggested that G. pulex did not return to the surface to feed after entering the hyporheic zone. This result contrasts with recent studies suggesting that leaf litter decomposition will increase 
312 with rising water temperatures due to enhanced microbial decomposition and invertebrate activity rates (e.g.,

1

9

Ferreira and Canhoto 2015, Mas-Martí et al. 2015). However, we argue that decomposition rates will be reduced when rising temperatures are coupled with contraction and drying of aquatic habitats and subsequent competition for resources due to the behavioral response of shredding invertebrates to enter the hyporheic zone. Implications of these findings are important considering G. pulex were responsible for an estimated $13 \%$ of leaf litter consumption in a wooded stream (Mathews 1967) and several other invertebrate shredders (e.g., Leuctridae, Leptoceridae) are known to use the hyporheic zone during disturbances (Stubbington 2012). An important next step will be to test if invertebrates are able to track diel water temperature changes, returning to the surface at night when surface temperatures are cooler to feed and how this may compensate for energy loss during the day. River invertebrates face a tradeoff between tolerating harsh surface conditions versus avoiding them by entering the hyporheic zone, a strategy which may not be suitable for long-term survival. On one hand, lower water temperature, fewer conspecific interactions and the lack of large predators may entice invertebrates to migrate into the hyporheic zone during periods of low flow, flow cessation and drying. On the other hand, once in the hyporheic zone, food limitation, low oxygen concentration (Findlay 1995) and colmation (Descloux et al. 2013), especially in rivers impacted by agricultural land use, will reduce the capacity of the hyporheic zone to provide refuge. Furthermore, competitive and predatory interactions with hypogean taxa (e.g., Schmid and Schmid-Arraya 1997) are likely to occur, although quantifiable evidence must be explored further. These interactions may have negative or positive effects on the resilience of surface invertebrates, depending on the outcome of these interactions. Therefore, the potential cascading effects of hyporheic zone refuge use by invertebrates remains an important research gap that could be addressed through mesocosm experiments.

\section{Conclusion}

There is a strong need to understand the influence of factors, such as water temperature and biotic interactions, that coincide with low flow, flow cessation and drying on river communities, especially considering global change will continue exacerbate their negative effects on river systems (Postel 2000, Datry et al. 2014, Jaeger et al. 2014). In many regions, once perennial rivers are now becoming intermittent (Datry et al. 2014), therefore future studies could explore how trait variability (Violle et al. 2012) and differences in physiological tolerance (Stoks et al. 2014) among populations from formally perennial and naturally intermittent rivers influence the response to increased temperature and biotic interactions. Although rare in freshwater ecology, the use of common garden experiments (i.e., simultaneously subjecting different populations to the same stressor) have 
342 revealed strong inter-population differences in temperature tolerance within aquatic species (e.g., Foucreau et al.

1 2343

3

2014). Therefore, such approaches could be developed to explore the responses of populations from perennial and intermittent rivers to other environmental factors associated with river contraction and drying. These experiments will in turn help refine the predictions of population and community responses to global climate change and increased water abstraction.

\section{Acknowledgements}

348 This project was funded by the Rhône-Méditerranée-Corse Water Agency through the "Invertebrate community 349 resistance and resilience in intermittent rivers" project, with additional support for RV from IRSTEA.

350 Thoughtful discussions with Florian Malard were influential in the study design. We thank Maxence Forcellini, 351 Bertrand Launay and Guillaume Le Goff for helping collect and count G. pulex in the field and laboratory.

352 Andrew Boulton and Paul Wood provided excellent feedback and suggestions to improve this manuscript.

\section{Literature Cited}

Acuña V, Muñoz I, Giorgi A, Omella M, Sabater F, Sabater S (2005) Drought and postdrought recovery cycles in an intermittent Mediterranean stream: structural and functional aspects. Journal of the North American Benthological Society 24:919-933 doi:10.1899/04-078.1

Boersma KS, Bogan MT, Henrichs BA, Lytle DA (2014) Top predator removals have consistent effects on large species despite high environmental variability. Oikos 123:807-816 doi:10.1111/oik.00925

Boulton AJ (1989) Over-summering refuges of aquatic macroinvertebrates in two intermittent streams in central Victoria Australia. Transactions of The Royal Society of South Australia 113:23-34

Burnside WR, Erhardt EB, Hammond ST, Brown JH (2014) Rates of biotic interactions scale predictably with temperature despite variation. Oikos 123:1449-1456 doi:10.1111/oik.01199

Burrell GP, Ledger ME (2003) Growth of a stream-dwelling caddisfly (Olinga feredayi: Conoesucidae) on surface and hyporheic food resources. Journal of the North American Benthological Society 22:92-104 doi:10.2307/1467980 
Capderrey C, Datry T, Foulquier A, Claret C, Malard F (2013) Invertebrate distribution across nested geomorphic features in braided-river landscapes. Freshwater Science 32:1188-1204 doi:10.1899/12188.1

Constantz J, Thomas CL (1997) Stream bed temperature profiles as indicators of percolation characteristics beneath arroyos in the middle Rio Grande Basin, USA. Hydrological Processes 11:1621-1634 doi:10.1002/(SICI)1099-1085(19971015)11:12<1621::AID-HYP493>3.0.CO;2-X

Corti R, Datry T, Drummond L, Larned ST (2011) Natural variation in immersion and emersion affects breakdown and invertebrate colonization of leaf litter in a temporary river. Aquatic Sciences 73:537550 doi:10.1007/s00027-011-0216-5

Danger M, Cornut J, Elger A, Chauvet E (2012) Effects of burial on leaf litter quality, microbial conditioning and palatability to three shredder taxa. Freshwater Biology 57:1017-1030 doi:10.1111/j.13652427.2012.02762.x

Dangles O, Malmqvist B (2004) Species richness-decomposition relationships depend on species dominance. Ecology Letters 7:395-402 doi:10.1111/j.1461-0248.2004.00591.x

Datry T, Corti R, Claret C, Philippe M (2011) Flow intermittence controls leaf litter breakdown in a French temporary alluvial river: the "drying memory". Aquatic Sciences 73:471-483 doi:10.1007/s00027-011$0193-8$

Datry T (2012) Benthic and hyporheic invertebrate assemblages along a flow intermittence gradient: effects of duration of dry events. Freshwater Biology 57:563-574 doi:10.1111/j.1365-2427.2011.02725.x

Datry T, Larned ST, Tockner K (2014) Intermittent rivers: a challenge for freshwater ecology. BioScience doi: 10.1093/biosci/bit1027

Dehedin A, Maazouzi C, Puijalon S, Marmonier P, Piscart C (2013) The combined effects of water level reduction and an increase in ammonia concentration on organic matter processing by key freshwater shredders in alluvial wetlands. Global Change Biology 19:763-774 doi:10.1111/gcb.12084

Descloux S, Datry T, Marmonier P (2013) Benthic and hyporheic invertebrate assemblages along a gradient of increasing streambed colmation by fine sediment. Aquatic Sciences 75:493-507 doi:10.1007/s00027013-0295-6 
Dole-Olivier MJ, Marmonier P, Beffy JL (1997) Response of invertebrates to lotic disturbance: is the hyporheic zone a patchy refugium? Freshwater Biology 37:257-276 doi:10.1046/j.1365-2427.1997.00140.x

Elliott JM (2005) Day-night changes in the spatial distribution and habitat preferences of freshwater shrimps, Gammarus pulex, in a stony stream. Freshwater Biology 50:552-566 doi:10.1111/j.13652427.2005.01345.x

Evans EC, Petts GE (1997) Hyporheic temperature patterns within riffles. Hydrological Sciences Journal 42:199-213 doi:10.1080/02626669709492020

Fairchild MP, Holomuzki JR (2005) Multiple predator effects on microdistributions, survival, and drift of stream hydropsychid caddisflies. Journal of the North American Benthological Society 24:101-112 doi:10.1899/0887-3593(2005)024<0101:MPEOMS>2.0.CO;2

Ferreira V, Canhoto C (2015) Future increase in temperature may stimulate litter decomposition in temperate mountain streams: evidence from a stream manipulation experiment. Freshwater Biology doi:10.1111/fwb.12539

Findlay S (1995) Importance of surface-subsurface exchange in stream ecosystems: The hyporheic zone. Limnology and Oceanography 40:159-164 doi:10.4319/lo.1995.40.1.0159

Foucreau N, Piscart C, Puijalon S, Hervant F (2013) Effect of climate-related change in vegetation on leaf litter consumption and energy storage by Gammarus pulex from continental or Mediterranean populations. PloS ONE 8:e77242 doi:10.1371/journal.pone.0077242

Foucreau N, Cottin D, Piscart C, Hervant F (2014) Physiological and metabolic responses to rising temperature in Gammarus pulex (Crustacea) populations living under continental or Mediterranean climates. Comparative Biochemistry and Physiology Part A, Molecular \& Integrative Physiology 168:69-75 doi:10.1016/j.cbpa.2013.11.006

Heino J, Melo AS, Siqueira T, Soininen J, Valanko S, Bini LM (2015) Metacommunity organisation, spatial extent and dispersal in aquatic systems: patterns, processes and prospects. Freshwater Biology 60:845869 doi:10.1111/fwb. 12533 
Hervant F, Mathieu J, Garin D, Fréminet A (1995) Behavioral, ventilatory, and metabolic responses to severe hypoxia and subsequent recovery of the hypogean Niphargus rhenorhodanensis and the epigean Gammarus fossarum (Crustacea: Amphipoda). Physiological Zoology:223-244

Hervant F, Mathieu J, Barré H, Simon K, Pinon C (1997) Comparative study on the behavioral, ventilatory, and respiratory responses of hypogean and epigean crustaceans to long-term starvation and subsequent feeding. Comparative Biochemistry and Physiology Part A: Physiology 118:1277-1283

Hervant F, Mathieu J, Barré H (1999) Comparative study on the metabolic responses of subterranean and surface-dwelling amphipods to long-term starvation and subsequent refeeding. Journal of Experimental Biology 202 24:3587-3595

Holomuzki JR, Biggs BJ (2007) Physical microhabitat effects on 3-dimensional spatial variability of the hydrobiid snail, Potamopyrgus antipodarum. New Zealand Journal of Marine and Freshwater Research 41:357-367 doi:10.1080/00288330709509925

Jaeger KL, Olden JD, Pelland NA (2014) Climate change poised to threaten hydrologic connectivity and endemic fishes in dryland streams. Proceedings of the National Academy of Sciences doi:10.1073/pnas.1320890111

James AB, Dewson ZS, Death RG (2008) Do stream macroinvertebrates use instream refugia in response to severe short-term flow reduction in New Zealand streams? Freshwater Biology 53:1316-1334 doi:10.1111/j.1365-2427.2008.01969.x

Jiang L, Morin PJ (2004) Temperature-dependent interactions explain unexpected responses to environmental warming in communities of competitors. Journal of Animal Ecology 73:569-576 doi:10.1111/j.00218790.2004.00830.x

Kaushal SS et al. (2010) Rising stream and river temperatures in the United States. Frontiers in Ecology and the Environment 8:461-466 doi:10.1890/090037

Kawanishi R, Inoue M, Dohi R, Fujii A, Miyake Y (2013) The role of the hyporheic zone for a benthic fish in an intermittent river: a refuge, not a graveyard. Aquatic Sciences 75:425-431 doi:10.1007/s00027-013$0289-4$ 
Keppel G, Mokany K, Wardell-Johnson GW, Phillips BL, Welbergen JA, Reside AE (2015) The capacity of refugia for conservation planning under climate change. Frontiers in Ecology and the Environment 13:106-112 doi:10.1890/140055

Lake PS (2003) Ecological effects of perturbation by drought in flowing waters. Freshwater Biology 48:11611172 doi:10.1046/j.1365-2427.2003.01086.x

Ludlam JP, Magoulick DD (2010) Environmental conditions and biotic interactions influence ecosystem structure and function in a drying stream. Hydrobiologia 644:127-137 doi:10.1007/s10750-010-0102-5

MacNeil C, Dick JTA, Elwood RW (1997) The trophic ecology of freshwater Gammarus spp. (Crustacea: Amphipoda): problems and perspectives concerning the functional feeding group concept. Biological Reviews 72:349-364 doi:10.1111/j.1469-185X.1997.tb00017.x

Mantua N, Tohver I, Hamlet A (2010) Climate change impacts on streamflow extremes and summertime stream temperature and their possible consequences for freshwater salmon habitat in Washington State. Climatic Change 102:187-223 doi:10.1007/s10584-010-9845-2

Mas-Martí E, Muñoz I, Oliva F, Canhoto C (2015) Effects of increased water temperature on leaf litter quality and detritivore performance: a whole-reach manipulative experiment. Freshwater Biology 60:184-197 doi:10.1111/fwb.12485

Mathers KL, Millett J, Robertson AL, Stubbington R, Wood PJ (2014) Faunal response to benthic and hyporheic sedimentation varies with direction of vertical hydrological exchange. Freshwater Biology 59:2278-2289 doi:10.1111/fwb.12430

Mathews C (1967) The energy budget and nitrogen turnover of a population of Gammarus pulex in a small woodland stream. Journal of Animal Ecology 36:62-69

Mouthon J, Daufresne M (2006) Effects of the 2003 heatwave and climatic warming on mollusc communities of the Saône: a large lowland river and of its two main tributaries (France). Global Change Biology 12:441-449 doi:10.1111/j.1365-2486.2006.01095.x

Navel S, Mermillod-Blondin F, Montuelle B, Chauvet E, Simon L, Piscart C, Marmonier P (2010) Interactions between fauna and sediment control the breakdown of plant matter in river sediments. Freshwater Biology 55:753-766 doi:10.1111/j.1365-2427.2009.02315.x 
Nogaro G, Mermillod-Blondin F, Valett M, François-Carcaillet F, Gaudet J-P, Lafont M, Gibert J (2009)

Ecosystem engineering at the sediment-water interface: bioturbation and consumer-substrate interaction. Oecologia 161:125-138 doi:10.1007/s00442-009-1365-2

Olsen DA, Townsend CR (2003) Hyporheic community composition in a gravel-bed stream: influence of vertical hydrological exchange, sediment structure and physicochemistry. Freshwater Biology 48:13631378 doi:10.1046/j.1365-2427.2003.01097.x

Ormerod SJ, Dobson M, Hildrew AG, Townsend CR (2010) Multiple stressors in freshwater ecosystems. Freshwater Biology 55:1-4 doi:10.1111/j.1365-2427.2009.02395.x

Palmer MA, Bely AE, Berg KE (1992) Response of invertebrates to lotic disturbance: a test of the hyporheic refuge hypothesis. Oecologia 89:182-194 doi:10.1007/BF00317217

Piscart C et al. (2011) Leaf litter recycling in benthic and hyporheic layers in agricultural streams with different types of land use. Science of The Total Environment 409:4373-4380 doi:http://dx.doi.org/10.1016/j.scitotenv.2011.06.060

Postel SL (2000) Entering an era of water scarcity: the challenges ahead. Ecological Applications 10:941-948 doi:10.1890/1051-0761(2000)010[0941:EAEOWS]2.0.CO;2

Power ME, Matthews WJ, Stewart AJ (1985) Grazing minnows, piscivorous bass, and stream algae: dynamics of a strong interaction. Ecology 66:1448-1456 doi:10.2307/1938007

Salin K, Voituron Y, Mourin J, Hervant F (2010) Cave colonization without fasting capacities: an example with the fish Astyanax fasciatus mexicanus. Comparative Biochemistry and Physiology Part A, Molecular \& Integrative Physiology 156:451-457 doi:10.1016/j.cbpa.2010.03.030

Scherr MA, Wooster DE, Rao S (2010) Effects of temperature on growth rate and behavior of Epeorus albertae (Ephemeroptera: Heptageniidae) nymphs. Environmental Entomology 39:2017-2024 doi:10.1603/en09247

Schmid PE, Schmid-Araya JM (1997) Predation on meiobenthic assemblages: resource use of a tanypod guild (Chironomidae, Diptera) in a gravel stream. Freshwater Biology 38:67-91 doi:10.1046/j.1365- 
Author-produced version of the article published in Aquatic Sciences, 2017, 79 (1), 45-55. The original publication is available at https://link.springer.com/article/10.1007/s00027-016-0478-z doi : 10.1007/s00027-016-0478-z

498

1

Silver P, Cooper JK, Palmer MA, Davis EJ (2000) The arrangement of resources in patchy landscapes: effects on distribution, survival, and resource acquisition of chironomids. Oecologia 124:216-224 doi:10.1007/s004420050009

Stanley EH, Buschman DL, Boulton AJ, Grimm NB, Fisher SG (1994) Invertebrate resistance and resilience to intermittency in a desert stream. American Midland Naturalist 131:288-300 doi:10.2307/2426255

Stewart B, Close P, Cook P, Davies P (2013a) Upper thermal tolerances of key taxonomic groups of stream invertebrates. Hydrobiologia 718:131-140 doi:10.1007/s10750-013-1611-9

Stewart RI et al. (2013b) Mesocosm experiments as a tool for ecological climate-change research. Advances in Ecological Research 48:71-181

Stoks R, Geerts AN, De Meester L (2014) Evolutionary and plastic responses of freshwater invertebrates to climate change: realized patterns and future potential. Evolutionary Applications 7:42-55 doi:10.1111/eva.12108

Stubbington R, Wood PJ, Reid I, Gunn J (2011) Benthic and hyporheic invertebrate community responses to seasonal flow recession in a groundwater-dominated stream. Ecohydrology 4:500-511 doi:10.1002/eco.168

Stubbington R (2012) The hyporheic zone as an invertebrate refuge: a review of variability in space, time, taxa and behaviour. Marine and Freshwater Research 63:293-311 doi:10.1071/MF11196

Vadher AN, Stubbington R, Wood PJ (2015) Fine sediment reduces vertical migrations of Gammarus pulex (Crustacea: Amphipoda) in response to surface water loss. Hydrobiologia:1-11 doi:10.1007/s10750015-2193-5

van Vliet MTH, Franssen WHP, Yearsley JR, Ludwig F, Haddeland I, Lettenmaier DP, Kabat P (2013) Global river discharge and water temperature under climate change. Global Environnemental Change 23:450464 doi:http://dx.doi.org/10.1016/j.gloenvcha.2012.11.002

Violle C et al. (2012) The return of the variance: intraspecific variability in community ecology. Trends in Ecology \& Evolution 27:244-252 doi:10.1016/j.tree.2011.11.014 
Author-produced version of the article published in Aquatic Sciences, 2017, 79 (1), 45-55.

523 Welton JS (1979) Life-history and production of the amphipod Gammarus pulex in a Dorset chalk stream. 2524

3

4

525

526

527

10

11

12

13

14

15

16

17

18

19

20

21
Freshwater Biology 9:263-275 doi:10.1111/j.1365-2427.1979.tb01508.x

Wenger SJ et al. (2011) Flow regime, temperature, and biotic interactions drive differential declines of trout species under climate change. Proceedings of the National Academy of Sciences 108:14175-14180 doi:10.1073/pnas.1103097108

White DS (1993) Perspectives on defining and delineating hyporheic zones. Journal of the North American Benthological Society 12:61-69 doi:10.2307/1467686

Williams DD, Moore KA (1985) The role of semiochemicals in benthic community relationships of the lotic amphipod Gammarus pseudolimnaeus: a laboratory analysis. Oikos 44:280-286 doi:10.2307/3544701

Wood PJ, Boulton AJ, Little S, Stubbington R (2010) Is the hyporheic zone a refugium for aquatic macroinvertebrates during severe low flow conditions? Fundamental and Applied Limnology 176:377390 doi:10.1127/1863-9135/2010/0176-0377

Wooster DE, DeBano SJ, Madsen A (2011) Predators are more important than conspecifics and water temperature in influencing the microdistribution and behavior of a detritivorous stonefly. Fundamental and Applied Limnology 179:215-223 doi:10.1127/1863-9135/2011/0179-0215 
Tables

1

2

3

4

5

6

9
Table 1. Results from 2-way ANOVA testing the effect of temperature and species density and their interaction on dependent variables related to $G$. pulex. Percentages were $\arcsin (\sqrt{ }$-x $)$-transformed and leaf mass consumption rate, triglycerides and glycogen contents were $\log 10(x)$-transformed.

\begin{tabular}{llllll}
\hline Dependent variable & Factor & d.f. & MSS & $F$ & $P$ \\
\hline \% Migrated & Temperature (T) & 2 & 0.045 & 4.280 & 0.024 \\
& Density (D) & 2 & 0.119 & 11.354 & $<0.001$ \\
& T $\times$ D & 4 & 0.017 & 1.650 & 0.191 \\
\hline \% Survivorship & Temperature (T) & 2 & 0.343 & 65.869 & $<0.001$ \\
& Density (D) & 2 & 0.008 & 1.559 & 0.229 \\
& T $\times$ D & 4 & 0.029 & 5.640 & 0.002 \\
\hline \multirow{2}{*}{ Leaf mass consumption } & Temperature (T) & 2 & 1.975 & 38.091 & $<0.001$ \\
& Density (D) & 2 & 1.087 & 15.120 & $<0.001$ \\
& T $\times$ D & 4 & 1.734 & 15.931 & $<0.001$ \\
\hline Triglycerides content & Temperature (T) & 2 & 0.959 & 0.727 & 0.493 \\
& Density (D) & 2 & 0.940 & 0.459 & 0.637 \\
& T $\times$ D & 4 & 1.082 & 1.240 & 0.319 \\
\hline Glycogen content & Temperature (T) & 2 & 2.869 & 2.461 & 0.105 \\
& Density (D) & 2 & 2.517 & 0.563 & 0.577 \\
& T $\times$ D & 4 & 3.902 & 4.013 & 0.012 \\
\hline
\end{tabular}


561 Table 2. Mean ( \pm SD) percent survivorship of G. pulex in different temperature and species density

1

\begin{tabular}{cccc}
\hline Temperature & Species density & Mean & Min. - Max. \\
\hline \multirow{2}{*}{$15^{\circ} \mathrm{C}$} & low & $61 \pm 8$ & $55-73$ \\
& medium & $62 \pm 8$ & $54-71$ \\
& high & $67 \pm 6$ & $58-72$ \\
\hline \multirow{2}{*}{$20^{\circ} \mathrm{C}$} & low & $79 \pm 5$ & $73-85$ \\
& medium & $67 \pm 4$ & $62-70$ \\
& high & $63 \pm 3$ & $59-67$ \\
\hline \multirow{2}{*}{$25^{\circ} \mathrm{C}$} & low & $34 \pm 12$ & $23-48$ \\
& medium & $35 \pm 2$ & $33-37$ \\
& high & $48 \pm 7$ & $42-57$ \\
\hline
\end{tabular}


Figure Legends

1

Figure 1. Experimental set-up of mesocosms $(n=36)$ used to test the effect of water temperature, species density and their interaction on the migration of $G$. pulex into the hyporheic zone.

Figure 2. Mean ( \pm SE) proportion (percent) of G. pulex that migrated into the hyporheic zone at different temperature and species density treatment conditions. Percent migrated into hyporheic zone is based on the initial species density.

Figure 3. Mean ( \pm SE) leaf mass consumption rate of $G$. pulex $\left(\mathrm{mg}\right.$. ind $^{-1}$ day $\left.^{-1}\right)$ at different temperature and species density treatment conditions. Calculation based on initial species density.

Figure 4. Mean ( \pm 1 S.E) individual triglycerides ( $\mu$ mol.g ${ }^{-1}$ dry mass) (A) and glycogen content $\left(\mu \mathrm{mol.g} \mathrm{g}^{-1}\right.$ dry mass) (B) of G. pulex at different temperature and species density treatment conditions. 
Figure 1.

1

2

3

4

5

6

7

8

9

10

11

12

13

14

15

16

17

18

19

20

21

22

23

24

25

26

27

28

29

30

31

32593

33

34

35594

36

37

38

39

40

41

42

43

44

45597

46

47

48598

49

50

51599

52

53

54600

55

56

57601

58

59

60602

61

62

63

64

65

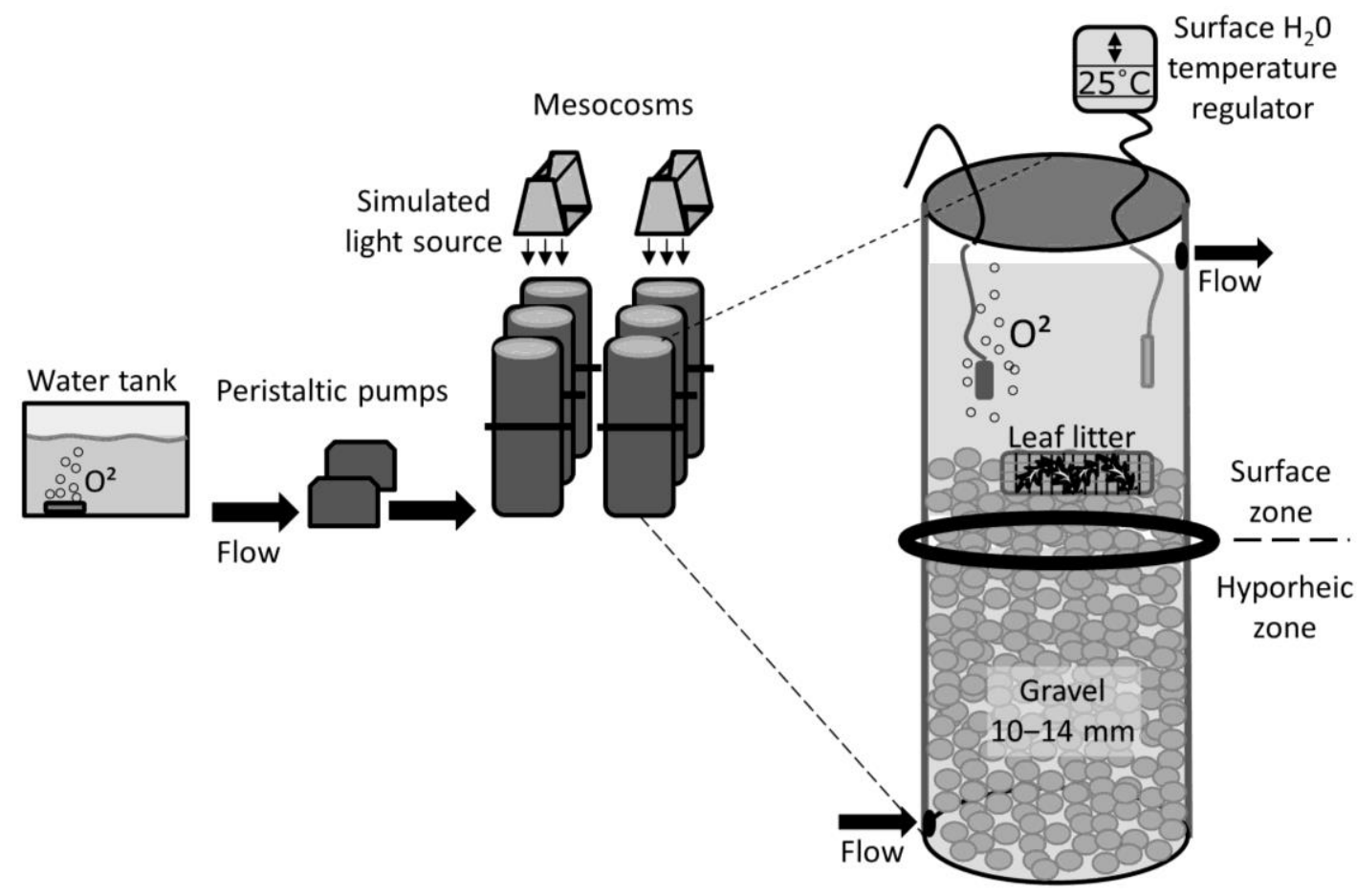


Author-produced version of the article published in Aquatic Sciences, 2017, 79 (1), 45-55. The original publication is available at https://link.springer.com/article/10.1007/s00027-016-0478-z doi : 10.1007/s00027-016-0478-z

\section{$603 \quad$ Figure 2.}

1

2

3604

4

5

6

7

8

9

10

11

12

13

14

15

16

17

18

19

20

21

22

23

24

25

26605

27

28606

29

30

31

32

33

34

35

36

37

38

39

40

41

42

43

44

45

46

47

48

49

50

51

52

53

54

55

56

57

58

59

60

61

62

63

64

65

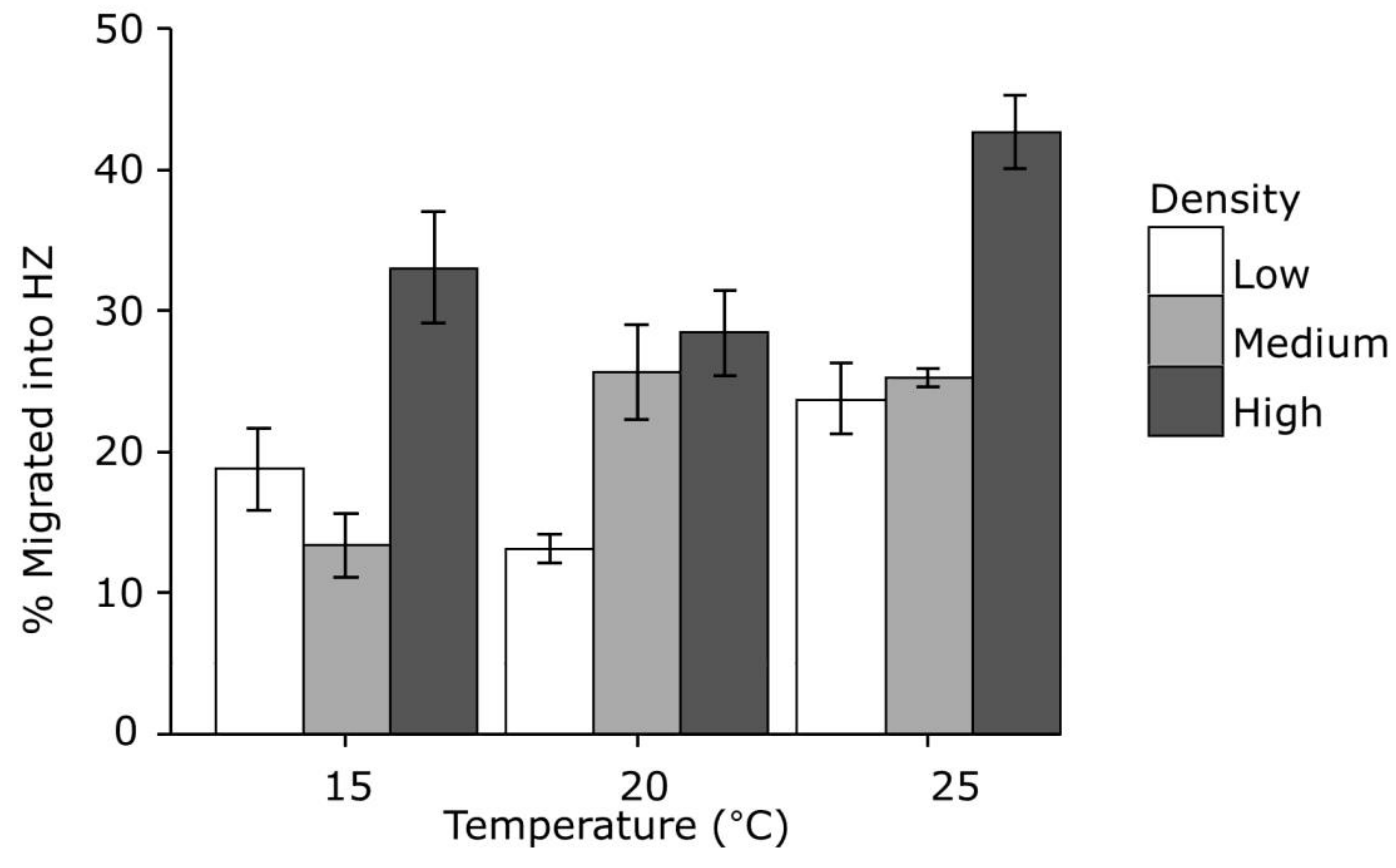


Author-produced version of the article published in Aquatic Sciences, 2017, 79 (1), 45-55.

Figure 3.

1

2

3608

4

5

6

7

8

9

10

11

12

13

14

15

16

17

18

19

20

21

22

23

24

25

26

27

28

29609

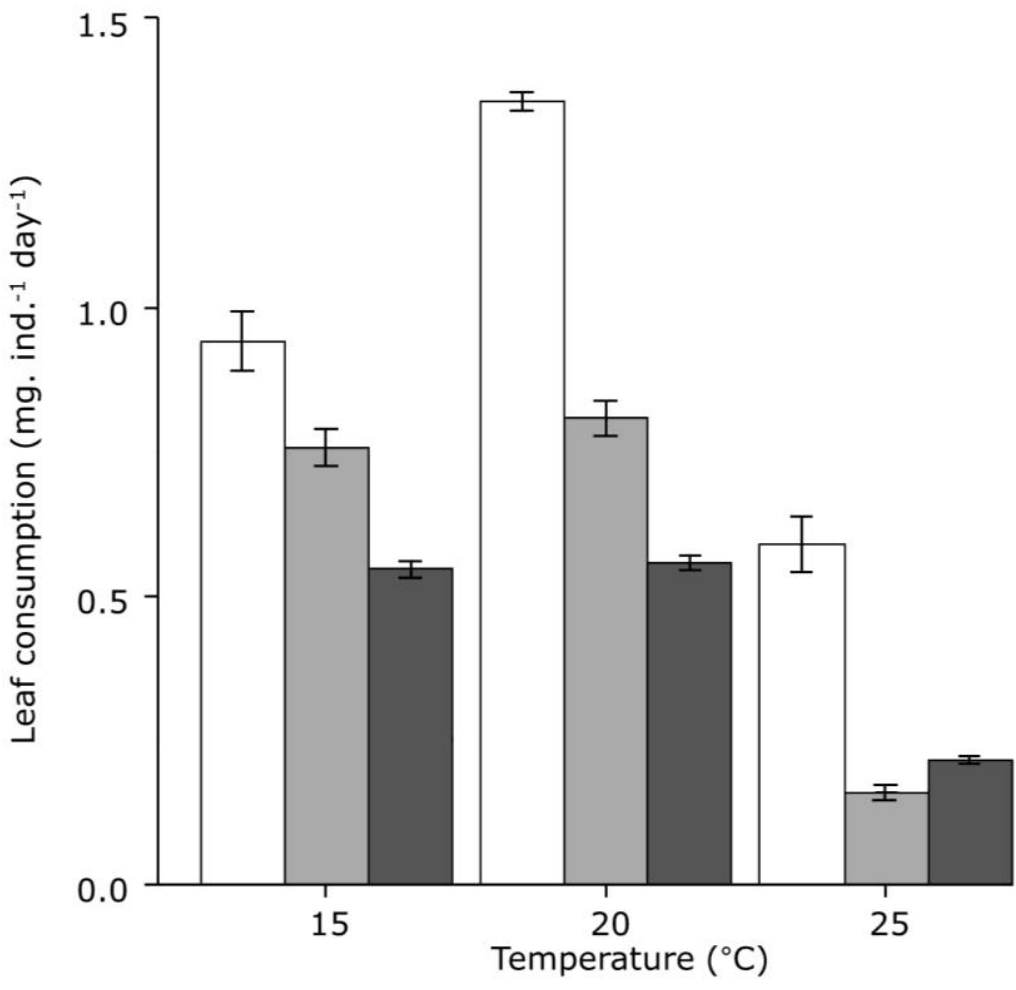

Density

30

31610

32

33

$\begin{array}{ll}34 & 611\end{array}$

36

37

38612

39

40

41613

42

43

44

45614

46

47

48615

49

50

51616

52

53

54

55617

56

57

58618

59

60

61

62

63

64

65 
Author-produced version of the article published in Aquatic Sciences, 2017, 79 (1), 45-55. The original publication is available at https://link.springer.com/article/10.1007/s00027-016-0478-z doi : 10.1007/s00027-016-0478-z

\section{$619 \quad$ Figure 4.}

1

2

3

4

5

6

7

8

9

10

11

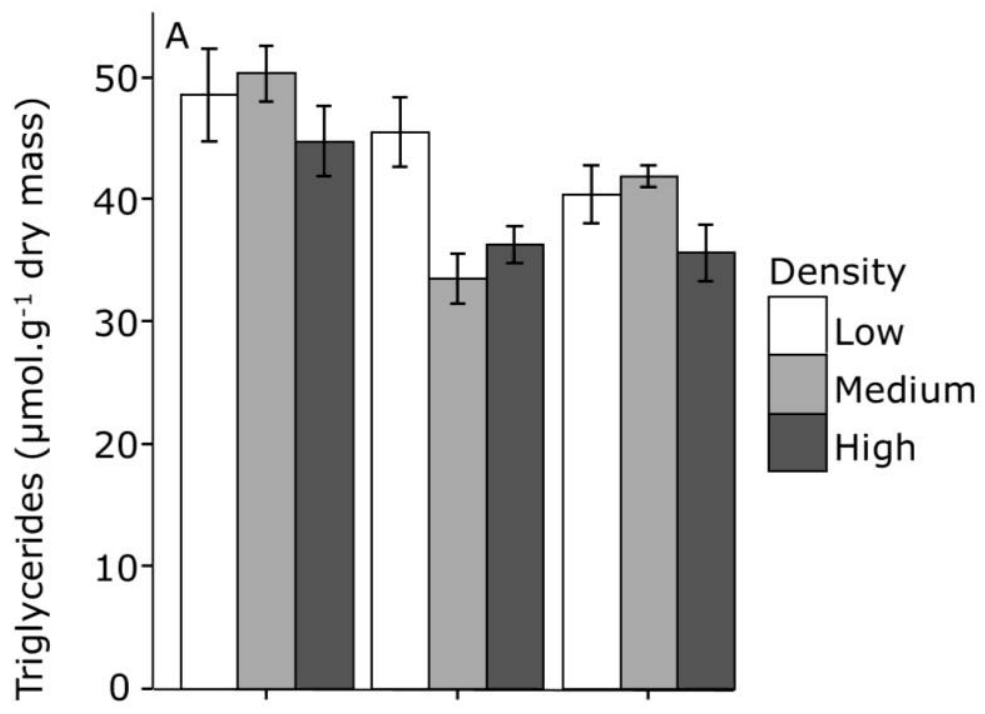

42

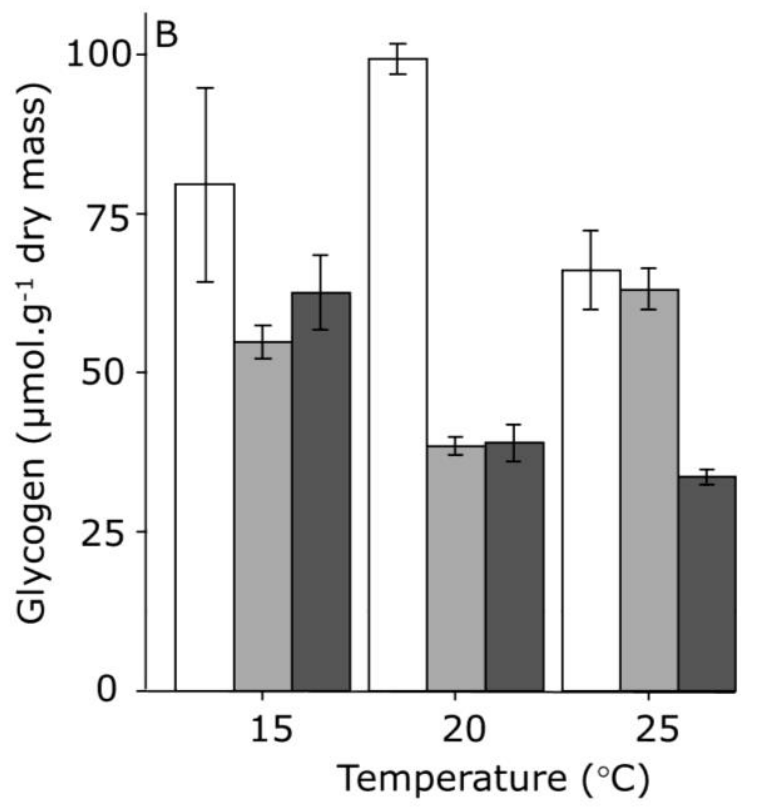




\section{Appendix SI}

1

628

629

630

10

\begin{tabular}{llllll}
\hline Dependent variable & Factor & d.f. & MSS & $F$ & $P$ \\
\hline Leaf mass consumption & Temperature (T) & 2 & 1.104 & 0.409 & 0.669 \\
& Density (D) & 2 & 1.920 & 9.943 & $<0.001$ \\
& T $\times$ D & 4 & 1.649 & 3.390 & 0.024 \\
\hline
\end{tabular}

